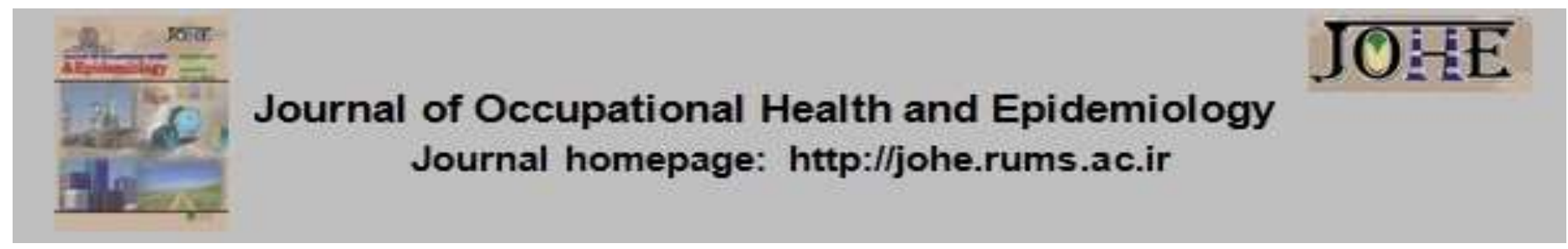

\title{
The Mediator Role of Procrastination in the association between Job Characteristics and Job Stress among Employees of Shahid Rajaee Customs Office, Bandar Abbas, Iran (2017)
}

\author{
Mohamad Ziaaddini ${ }^{1 *}$, Hasan Alinezhad ${ }^{2}$ \\ 1-Assistant Prof., Dept of Management, Rafsanjan Branch, Islamic Azad University, Rafsanjan, Iran. \\ 2- PhD Student, Dept of Management, Rafsanjan Branch, Islamic Azad University, Rafsanjan, Iran.
}

Citation: Ziaaddini M, Alinezhad H. The Mediator Role of Procrastination in the association
between Job Characteristics and Job Stress among Employees of Shahid Rajaee Customs
Office, Bandar Abbas, 2017. JOHE 2019; 8(4):221-5.

\section{Article Info}

* Corresponding author:

Mohamad Ziaaddini,

E-mail:

m.ziaaddini@yahoo.com

\section{Article history}

Received: Dec 2017

Accepted: Dec 2019

10.29252/johe.8.4.221

Print ISSN: 2251-8096 Online ISSN: 2252-0902

Peer review under
responsibility of Journal of
Occupational Health and

Epidemiology

\begin{abstract}
Background: This study aimed to examine the association between job characteristics and procrastination with the mediating role of job stress among the official staff of Shahid Rajaee Customs Office, Bandar Abbas, Iran, 2017.

Materials and Methods: This descriptive research is a pathway analysis. The statistical population included all staff members $(n=650)$ at Shahid Rajaee Customs Office. Based on the Guernsey and Morgan's table, 242 staff were selected as the samples through random sampling. To collect data, we employed three questionnaires, including job characteristics, job stress, and procrastination questionnaires. The content validity of the instruments was approved. In addition, reliability was reported at $0.78,0.79$, and 0.86 for the abovementioned questionnaires, respectively. The data were analyzed using Pearson's correlation coefficient and regression. Statistical analysis was performed using SPSS Statistics software V.21.0.

Results: A significant association was observed between job characteristics and procrastination $(r=-0.420, P<0.01)$. Moreover, a significant negative association was found between job stress and procrastination in the staff $(r=0.538, P<0.01)$. According to the results of the present research, job stress could mediate the association between job characteristics and procrastination.
\end{abstract}

Conclusion: According to the importance job characteristics theory, it could be used in decreasing job stress in organizations.

Keywords: Procrastination, Job Stress, Employees

\section{Introduction}

Human resources are considered as the most valuable capitals of organizations. Thus, organizations are required to make an effective use of their human resources to achieve their objectives and to meet environmental challenges. To this end, one of the efforts made by organizations to retain their human resources is to identify factors reducing stress [1].

Job stress is an emotional response produced when job conditions and possibilities are not consistent with workforce capacity, resources, and needs. Moreover, individual factors, such as character defects, personality traits, and coping strategies could lead to its incidence [2]. Under such conditions, job stress could have negative impacts on job satisfaction, absenteeism, as well as job burnout. It should be noted that job stress outcomes are not limited to the workplace, and they could influence other life aspects [3]. In this regard, organizational procrastination refers to the act of postponing, suspending, and disregarding duties and responsibilities as well as leaving actions for the future. Stress and anxiety are 
among the consequences of procrastination which could lead to the waste of time and resources in individuals and organizations, thereby exerting a negative impact on health status [4].

According to Schraw (2007), behavior considered as procrastination is needless, delaying, and counterproductive [5]. Lay (1976) describes procrastination as frequent failure to do what needs to be done to reach goals [6]. Job characteristics are among the factors affecting employee behavior in an organization. In this study, the dimensions of the job characteristics model has been used as the basic theory. Herzberg (1978) believes some factors in the workplace lead to job satisfaction while a separate group of factors leads to dissatisfaction, which are all independent of each other. However, unlike Herzberg's theory that a specific advice is not provided for a job, the job characteristics theory of work considers job design [7].

Therefore, given the theoretical background of this study and lack of research in this field, this research attempts to examine the association between job characteristics and job stress by taking into account the mediator variable of procrastination at Shahid Rejaee Customs Office, Iran.

\section{Materials and Methods}

This descriptive research uses pathway analysis and primary data collected through questionnaires. The respondents were assured that all their responses would be kept confidential. This study emphasized the use of close-ended questionnaires which were responded to, based on a 4-point Likert scale to determine the level of interest in and perception of each element. All questionnaire items were analyzed using SPSS Statistics V.21.0 (IBM Corporation, Armonk, NY, USA).

The statistical population included all employees $(n=242)$ at Shahid Rajaee Customs Office located in Bandar Abbas in 2017. Based on the Guernsey and Morgan's table (Table 2), 95 subjects were selected as the samples through random sampling. Three questionnaires of job characteristics, neglect, and job stress were used. The questionnaires were taken from previous studies and modified to fit the current context. The questionnaires consisted of items related to distributed job stress (13 questions), distributed job characteristics (15 questions), and items for measuring neglect (29 questions). All questionnaires had proper validity and reliability. They were scored on a 4-point Likert scale of 'strongly agree', 'agree', 'strongly disagree', and 'disagree' with the weights of $4,3,2$, and 1 , respectively.

\section{Results}

According to the analysis of the data obtained from the participants, 134 individuals (55.4\%) were male and 108 individuals (44.6\%) were female. In addition, 215 individuals (88.8\%) were married and 27 individuals $(11.2 \%)$ were single. In terms of the level of education, 67 participants $(27.7 \%)$ had a high school diploma, and 29 individuals (12.0\%) held an associate's degree. In addition, 74 individuals $(30.6 \%)$ had a bachelor's degree, and 72 of them (29.8\%) held master's and postgraduate degrees.

Table 1. Kolmogorov-Smirnov test for the assumption of the normality of research variables

\begin{tabular}{lccc}
\hline Variable & Job Characteristics & Job stress & Procrastination \\
\hline Kolmogorov-Smirnov test & 1.678 & 1.223 & 0.967 \\
\hline Significance level & 0.07 & 0.100 & 0.307 \\
\hline
\end{tabular}

The second assumption reviewed was the presence of a linear association between the research variables, which was separately examined for all these variables. For the presence of a linear association between the research variables, the probability of the $\mathrm{F}$-value in the linear factor needed not to exceed 0.05 . In the present study, the probability of the F-value in the linear factor was not greater than 0.05 in each association, which indicated the presence of a linear association between the research variables. The first step in the path analysis model after reviewing the assumptions was to investigate the correlation matrix between the variables (Table 1).

Table 2. Correlation matrix

\begin{tabular}{lccc}
\hline Variables & Job characteristics & Job stress & Procrastination \\
\hline Job characteristics & 1.000 & & \\
\hline Job stress & $-.495^{\star *}$ & 1.000 & 1.000 \\
\hline Procrastination & $-.420^{\star *}$ & $.538^{\star *}$ & \\
\hline
\end{tabular}

** Correlation was significant at a $99 \%$ confidence level. 
Based on Table 2, the association between job characteristics, job stress, and procrastination was negative; however, there was a positive correlation between job stress and procrastination. To test this hypothesis, the following steps were taken (Table 2).

Table 3. Regression model coefficients of procrastination, job characteristics, and job stress

\begin{tabular}{lccccc}
\hline Variables & Estimated B & Standard error & Estimated standard $\boldsymbol{\beta}$ & t-value & P-value \\
\hline Job characteristics & 0.427 & 0.061 & 0.409 & 6.975 & 0.000 \\
\hline Job stress & 0.360 & 0.076 & 0.280 & 4.768 & 0.000 \\
\hline
\end{tabular}

Since the beta values of the variables of job characteristics and job stress were significant at the error level of less than 0.001 , these variables had an effect on procrastination.

Accordingly, an increase of one unit in the variable of job stress increased the mean of procrastination by 0.360 (Table 3 ).

To calculate the standardized regression coefficient between job characteristics and job stress, the regression analysis was performed once more.

Procrastination was the dependent variable. To calculate $\beta 2$, a regression test had to be performed once again, so the standard beta coefficient between the two variables of job characteristics and job stress was calculated.

Table 4. Regression model coefficients of associations between job characteristics and job stress

\begin{tabular}{cccccc}
\hline Variables & Estimated B & Standard error & Estimated standard $\boldsymbol{\beta}$ & t-value & P-value \\
\hline Job characteristics & 0.434 & 0.062 & 0.460 & 6.786 & 0.000 \\
\hline
\end{tabular}

Where the dependent variable is job stress, we will have the following in the Fig 1 :

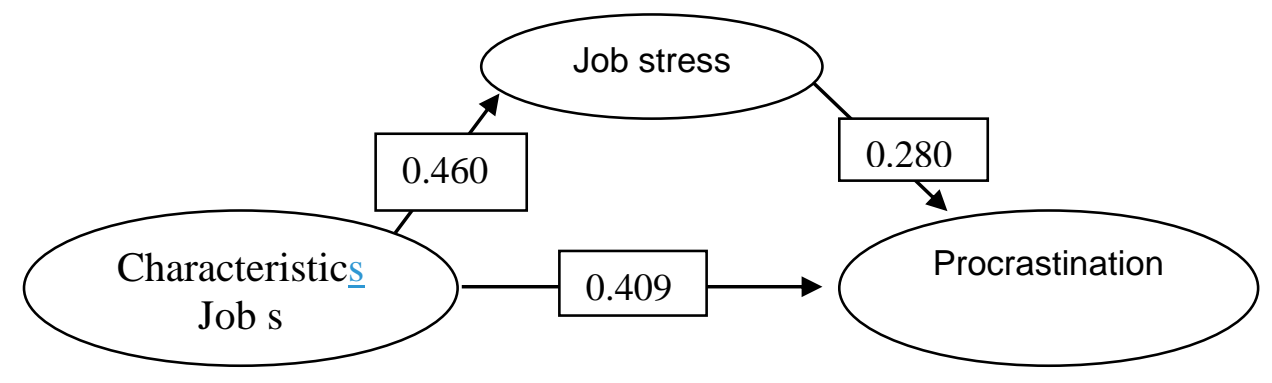

Fig.1. The results of path analysis for testing the hypothesis

Table 5. The effect of the total association of the variables

\begin{tabular}{ccc}
\hline Route & Direct impact & Total effect \\
\hline Job characteristics $\rightarrow$ Procrastination & 0.409 & $0 / 280 \times 0 / 460+(0 / 409)$ \\
\hline Job characteristics $\rightarrow$ Job stress & 0.460 & 0.460 \\
\hline Job stress $\rightarrow$ Procrastination & 0.280 & 0.280 \\
\hline
\end{tabular}

The following items are considered for the association between the variables:

If the total effect is less than 0.3 , the observed correlation will not be significant.

If the total effect is calculated between 0.3 and 0.6 , the observed correlation will be desirable.
If the total effect exceeds 0.6, the observed correlation will be highly desirable.

Since the total effect is equal to 0.537 being between 0.3 and 0.6 , the correlation is desirable. However, this analysis has not yet been completed (Table 5).

Table 6. Model summary for error calculation

\begin{tabular}{ccccc}
\hline Estimated Standard error & R2adj & $\mathbf{R 2}$ & $\mathbf{R}$ & Model \\
\hline 0.419 & 0.346 & 0.351 & 0.593 & \\
\hline
\end{tabular}

Based on Table 6, the final step was taken to calculate the error as follows:

e2 $=0 / 649=0 / 351-1$

The values of $\mathrm{R} 2$ and $\mathrm{e} 2$ were 0.351 and 0.65 , respectively, indicating that $35 \%$ of the variance of the dependent variable could be explained by the model, and that $65 \%$ of the remaining variables could not be explained as such.

Thus, we would have: 


\section{Discussion}

The main objective of this study was to investigate the effect of job characteristics on procrastination with a view of the mediating effect of job stress in the employees of Shahid Rajaee Customs Office in Bandar Abbas.

The independent variable was job characteristics, the dependent variable was neglect, and the mediator variable was job stress [8]. The results indicate that job characteristics have a direct effect on procrastination, which is consistent with the findings of the studies of Salamon, Jovkers, and Jobandeh. According to them, job characteristics affect job attitude and improve business outcomes. In addition, procrastination could be influenced by changes in the interpersonal variables of employees' occupational characteristics that affect employee procrastination [9].

In another study titled "nudity and stress in nurses", procrastination was reported to increase stress in nurses, which is consistent with the results of this study. In explaining this finding, one could argue that nurses are confronted with people of various traits in their work sectors, so their daily lives are fraught with unpleasant situations; thus, stress causes them to practice procrastination [10]. People with diverse job characteristics seem to be able to adapt to the environment inside and outside the organization according to their own characteristics. They make the right decision, which is the best way to choose the right way and practice neglect. According to the results, job stress has no mediator role in the association between job characteristics and procrastination. The results also indicate that job characteristics have a significant occupational impact on job performance, which is consistent with Akbari's findings. He believes that job characteristics lead to factors supporting people in tensions. Therefore, job characteristics could be considered as a promising concept to be used in preventive programs for various types of damage and reducing occupational stress [11].

A lot of studies have been done on this topic, which were compared with the present study. All findings of other studies were consistent with the current research, and there were no results to be exactly the same as the results of the present study. Considering the contradiction in different studies, two conclusions could be drawn. Firstly, other factors should be identified in the association between job characteristics and job stress. Secondly, the sample size of the current work was small, so the modeled variables were not significant. Thus, some other factors could be effective, and it is suggested that a larger sample size be considered in future research.

\section{Conclusion}

Based on the findings, job stress and job satisfaction exert significant impacts on increasing work-related procrastination among employees of the studied organization.

\section{Acknowledgement}

We would like to express our sincere gratitude to the managing director, research manager, and staff at Shahid Rajaee Customs Office for their support in performing this study.

Conflict of interest: None declared.

\section{References}

1. Steel P. The nature of procrastination: A metaanalytic and theoretical review of quintessential self-regulatory failure. Psychol Bull 2007; 133(1):65-94.

2. Schraw G, Wadkins T, Olafson L. Doing the things we do: A grounded theory of academic procrastination. J Educ Psychol 2007; 99(1):1225.

3. Hosseinabadi MB, Etemadinezhad S. Evaluating the association between job stress and job satisfaction among female hospital nurses in Babol: An application of structural equation modeling. Health Promot Perspect 2018; 8(2):102-8.

4. Solomon LJ, .Rothbluam ED. Academic procrastination: Frequency and cognitivebehavioural correlates. J Couns Psychol 1984; 31(4):503-9.

5. Mohammadi Sh, Maghsodi M. An investigation of the association between jobs stress and marital satisfaction among females personnel. Journal of Career \& Organizational Counseling 2012; 3(9):74-87.

6. Vosoughi Niri A, Rohollahi A, Mohamad Hossein $\mathrm{H}$. A Survey of effect of job stress on general health and job performance on Air Traffic Controllers (ATC) 2016; 13(1):47-57.

7. Nekoei Moghadam M, Beheshtifar M, Shokoh Saljoghi Z. Determining correlation between management styles and administrators' duties in Kerman University of Medical Sciences. Journal of Health Administration 2007; 10(29):37-44.

8. Dehghani Y, Asghari F, Saeidpour F, Joukar E. Prediction of occupational burnout based on job satisfaction, personality traits and mental health. Iranian Journal of Nursing Research 2017; 12(5):61-70.

9. Chahardoli S, Motamedzade M, Hamidi $Y$, Soltanian AR, Golmohammadi R. Investigating the association between psychosocial work stressors, organizational structure and job 
satisfaction among bank tellers. Journal of Health and Safety at Work 2015; 5(4):47-58.

10. Moshtagh Eshgh Z, Aghaeinejad AA, Peyman A, Amirkhani A, Chehregosha M. Association between Occupational Stress and Mental Health in Male Personnel of Medical Emergency in Golestan Province. Journal of Research
Development in Nursing and Midwifery 2015; 12(1):29-38.

11. Negahdari A, Jadid-Milani $M$, Alemohammad $\mathrm{SN}$, Pishgooei SAH. The association between job stress and quality of work life among prehospital emergency personnel in Shiraz, 2017. Iranian Journal of Nursing Research 2019; 13(6):48-53.

12. 